\title{
0 campo das políticas educacionais brasileiras em compasso de espera: o que virá?
}

Apresentamos a nossos leitores mais um número da RBPAE em um contexto que vem demandando de todos nós, estudiosos das políticas públicas educacionais, um grande esforço para assimilação e compreensão do momento político eleitoral que o país vivencia neste final de 2018. Passadas as eleições presidenciais e já conhecido o novo presidente da República para os próximos quatro anos, o país assiste ao que, no jargão político, denomina-se "transição de governos".

Dentre os muitos aspectos desta transição destacamos a composição da nova equipe de ministros, que tem na figura do economista Paulo Guedes, fundador de um banco e de alguns fundos de investimentos, um "importante" ministro, a quem foi delegada a tarefa de montar a equipe econômica no novo governo. De matriz ultra direitista, o principal critério de escolha das pessoas é que sejam alinhados com o ideário neoliberal, adeptos do Estado mínimo e da privatização de empresas e serviços públicos.

Mantém-se, portanto, a agenda construída pelo governo de Temer e acirram-se, ainda mais, as (contra) reformas iniciadas em 2016. As primeiras ações indicam que será mantida a EC 95/2016, que congela as despesas primárias do poder executivo até 2036; pautarão a reforma da previdência e, sinalizam para a possibilidade de reduzirem ainda mais os direitos dos trabalhadores. Em reiteradas vezes, o presidente eleito tem-se mostrado avesso às políticas sociais para redução da pobreza e da desigualdade, de inclusão das minorias sociais, e já deixou claro que não está sensível aos problemas climáticos globais.

No âmbito das políticas educacionais, o horizonte não se mostra diferente, tendo na figura de Ricardo Vélez Rodrigues, colombiano naturalizado brasileiro, indicado como ministro da educação, sem registro de nenhuma experiência na gestão de políticas públicas educacionais. Esse fato poderá incrementar ainda mais as ações de terceirização da gestão na Educação Básica, seguidas de políticas que flexibilizam e precarizam os contratos de trabalhos dos profissionais da educação, já legalizados pela reforma trabalhista em 2017. Além disso, expressou em diversos textos escritos anteriormente disseminados na mídia após a indicação de seu nome para o MEC, seus posicionamentos a favor do projeto "escola sem 
partido", contrários à discussão sobre gênero nas escolas e que vê na educação o "fantasma" da ideologização na formação e atuação dos professores, nas provas do ENEM, etc.

É nesse cenário de incertezas e desafios para a manutenção das conquistas sociais e educacionais no Brasil, que reiteramos nossa perspectiva crítica em defesa do Estado democrático de direito que se responsabilize pela cobertura social das populações mais pobres e vulneráveis, dos trabalhadores e trabalhadoras e de todos os cidadãos, inclusive aqueles privados de liberdade, de modo a garantir o cumprimento pleno da Constituição Federal de 1988 para todos os brasileiros e brasileiras, o que inclui a oferta de uma educação pública de qualidade social, gratuita, laica e capaz de contribuir para a promoção da justiça social.

A RBPAE tem expressado e registrado a sua posição em relação aos eventos políticos que desencadearam uma vigorosa onda conservadora no Brasil, em especial a partir dos movimentos de junho de 2013, já analisados neste espaço da revista em números anteriores. Trata-se, entretanto, de um complexo fenômeno social e político a ser ainda examinado em profundidade. Esperamos que venham muitos estudos e pesquisas que possam contribuir tanto para a compreensão como para a sugestão de ações que possam contribuir para a superação dessa onda, tão comprovadamente cruel para a maioria da população brasileira. Dados da ONG britânica Oxfam ${ }^{1}$, especializada em estudos sobre as disparidades sociais no planeta e divulgados em novembro de 2018, mostram que após o golpe de 2016 e durante o governo Temer, a extrema pobreza no Brasil cresceu de 13,3 para 15 milhões de pessoas, o que representa $7,2 \%$ da população. O relatório mostra ainda que a mortalidade infantil voltou a crescer pela primeira vez desde 1990 e, em 2016, registrou um aumento de 4,9\% em relação a 2015. Os dados também mostram aumento das desigualdades de renda entre negros e brancos e entre homens e mulheres.

É nesse contexto que apresentamos, neste número, artigos que abordam temáticas diversificadas como: gestão compartilhada via consórcios públicos, levantamentos bibliográficos de temáticas específicas e que refletem o escopo deste periódico, relação das teorias administrativas no campo da educação, mobilidade estudantil internacional, implementação de Programa de desenvolvimento da Educação de Jovens e Adultos, a Nova Gestão Pública, o caso de universidades regionais comunitárias, planos de carreira e tabelas salariais docentes e política de assistência educacional.

1 Disponível em: https://www.oxfam.org.br/publicacoes/cada-vez-mais-desigual/vamos-falar-sobredesigualdade, acesso em 09 dez 2018. 
Iniciamos a apresentação das publicações desse número com o artigo "Consórcio de educação de Barcelona: evidências de gestão compartilhada de serviços educativos via consórcios públicos”, de Thamara Caroline Strelec, Valeriano Mendes Ferreira Costa e Raquel Gallego Calderon, cujo objetivo é compreender o modelo de gestão dos Consórcios de educação de Barcelona e identificar seus resultados e desafios. $\mathrm{O}$ artigo reflete um tipo específico de acordo governamental para lidar com esforço coletivo na gestão de serviços públicos, demonstrando peculiaridades dessa ação em Barcelona.

Em seguida, Julian Silveira Diogo de Ávila Fontoura e Berenice Corsetti apresentam no estudo "A qualidade da educação superior em contexto emergente: uma aproximação na perspectiva da produção acadêmica recente (20072017)" a produção do conhecimento sobre a temática em questão por meio de levantamento das teses e dissertações publicadas e disponibilizadas na Biblioteca Digital Brasileira de Teses e Dissertações do Instituto Brasileiro de Informação em Ciência e Tecnologia (BDTD/IBICT).

Alexandre Simão Freitas, por meio do trabalho "Artes de governo, anarqueologia e assinaturas na geração de modelos analíticos no campo da Administração educacional", apresenta estudo teórico sobre a governamentalidade política estatal (grifo do autor), tendo como base autores como Foucault e Agamben, motivado pela escassez de estudos dos fundamentos ontológicos das teorias administrativas no campo educacional.

O artigo intitulado "Contornos da produção acadêmica sobre gestão democrática do ensino público em teses e dissertações da área da educação (1996-2015)", de Elton Luiz Nardi e Paula Fernanda Silveira Boiago, trata das características dos trabalhos sobre gestão democrática do ensino público na Educação Básica (grifo dos autores) no período de 1996 a 2015 publicadas no Catálogo de Teses e Dissertações da Capes, apresentando tendências da produção na área.

Ana Paula Perlin et al. destacam no trabalho "Fatores motivacionais e contribuições das mobilidades internacionais de estudantes de uma instituição federal do Rio Grande do Sul” as motivações e contribuições dessa mobilidade, com destaque para a identificação dos fatores condicionantes, se por realização pessoal ou por objetivos profissionais. Para isso, perpassam por referencial teórico que trata da mobilidade acadêmica internacional e apresentam os dados coletados na instituição participante.

"O processo de implantação do Proeja na cultura escolar da educação profissional", de Valdinei Marcolla, por meio de pesquisa documental e de campo, tem por objetivo refletir sobre o processo de implantação do Programa Nacional de Integração da Educação Profissional com a Educação Básica na Modalidade 
de Educação de Jovens e Adultos (PROEJA) em uma instituição federal do Rio Grande do Sul. Visa à compreensão da constituição do curso, integração curricular e relações com a cultura escolar.

$\mathrm{O}$ artigo "Os tensionamentos no ensino sob o regime do capitalismo acadêmico na nova economia: o caso das universidades comunitárias regionais", de Cristina Fioreze, possui como objetivo analisar as perspectivas e valores que orientam as universidades comunitárias regionais do Rio Grande do Sul, demonstrando suas tendências num contexto de tensionamento mercantil.

O trabalho de Cristiane Aparecida da Silva et al. intitulado "Política de Assistência Educacional e a Taxa de Sucesso da Graduação das Universidades Públicas Federais" analisa a eficiência das despesas com assistência educacional e sua relação com as taxas de sucesso das universidades públicas federais.

O estudo que fecha este número, de Michelle Fernandes Lima, Gisele Masson e Artur Lourival da Fonseca Machado, possui como título "Vencimentos dos professores das redes municipais das mesorregiões Sudeste e Centro-Oriental do Paraná". Trata da análise de diferenças salariais de professores da rede municipal de 35 municípios e das leis desses municípios sobre planos de carreira e tabelas salariais

Desejamos uma ótima leitura!

Lúcia Maria de Assis

Editora

Daniela da Costa Britto Pereira Lima

Editora Associada 